\title{
Shared Geocaching Over Distance with Mobile Video Streaming
}

\author{
Jason Procyk \\ School of Interactive Arts + \\ Technology \\ Simon Fraser University \\ 250 - $13450102^{\text {nd }}$ Avenue \\ Surrey, BC, Canada, V3T 0A3 \\ jep4@sfu.ca

\section{Carman Neustaedter} \\ School of Interactive Arts + \\ Technology \\ Simon Fraser University \\ $250-13450102^{\text {nd }}$ Avenue \\ Surrey, BC, Canada, V3T 0A3 \\ carman_neustaedter@sfu.ca

\section{Carolyn Pang} \\ School of Interactive Arts + \\ Technology \\ Simon Fraser University \\ $250-13450102^{\text {nd }}$ Avenue \\ Surrey, BC, Canada, V3T 0A3 \\ carolyn_pang@sfu.ca \\ Anthony Tang \\ University of Calgary \\ 2500 University Drive NW \\ Calgary, AB, Canada \\ tonyt@ucalgary.ca \\ Tejinder K. Judge \\ Google Inc. \\ 1600 Amphitheater Parkway \\ Mountain View, CA, USA \\ tkjudge@google.com
}

In the Video Program of the Conference on Computer Supported

Cooperative Work and Social Computing (CSCW 2014)

\begin{abstract}
Shared geocaching is an outdoor activity where pairs of individuals geocache together but in different locations. Video streaming allows two players to see each remote person's view and converse during the activity. This allows players to help each other out while searching for geocaches. We envision that shared geocaching will provide a way for family or friends to share experiences together over distance where they are both

participating in the same activity at the same time, only in different locations.
\end{abstract}

\section{ACM Classification Keywords}

Video conferencing, families, media space

\section{Author Keywords}

H.5.m. Information interfaces and presentation (e.g. $\mathrm{HCI}$ ): Miscellaneous.

\section{Introduction}

Video chat technologies allow family and friends to connect over distance so they can see and hear each other in real time. This has been found to create strong feelings of connection between distanceseparated family members [1][7][8]. Researchers have explored the use of video chat amongst family members [1], grandparents and grandchildren [16], teenagers [2], childhood friends [18], and even long- 


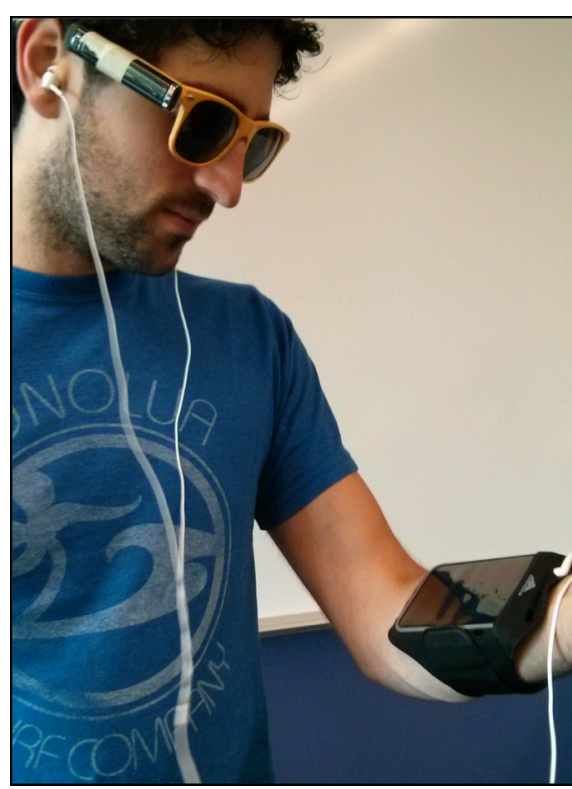

Figure 1: Our technology probe for shared geocaching. distance partners [11]. One dominant theme that has emerged is that, in addition to simply conversing, people enjoy sharing experiences together over distance, such as watching television, listening to music, doing art projects, etc [2][7].

Our interest was in exploring how mobile video chat could support the sharing of everyday outdoor activities between people who were geographically separated.

We were particularly interested in parallel experiences: situations where both the local and remote family member or friend were doing the same activity in parallel together, rather than one person passively watching the activity from home. This reflects many situations in life where co-located people, in parallel, go out and participate in an activity together (e.g. walking, running, playing sports, sightseeing). In these situations, people may not be sharing in the other person's activity, but they are in essence doing the same general activity at the same time and in the same location.

To explore this scenario, we created shared geocaching: geocaching amongst two people where each is in a different location and hunting for his or her own geocache. To support interactions over distance, we created a video streaming technology probe [10] that provides a view of each person's remote area along with an audio connection to support conversation (Figure 1). We envisioned that people could geocache together over distance and help each other out as needed or simply be 'together' while doing the activity. We chose to explore geocaching as it includes a range of activities, including walking or hiking, navigation, coordination, and socializing. Geocaching can also be done in a variety of areas, including urban settings.
This allows one to explore the use of video streaming in public settings. Geocaching has also been shown to make people feel more connected and emotionallyclose to others when they geocache together [13].

\section{Related Work}

Geocaching is a GPS-based treasure hunt where players search for hidden containers that include a logbook to sign one's initials. Geocaching originated in forests and parks but can now be found in everyday urban centers [4]. Research has shown that people geocache for a variety of reasons including experiencing new places, participating in activities with family and friends, giving purpose to walks, improving profile statistics, challenging oneself, and competing with others [5][15] We also know that geocaching has a strong sense of community where players create and maintain the game long term by hiding geocaches and monitoring their own caches and those of others [13]. To date, nobody has explored how geocaching may work amongst people who are separated by distance and wish to play together.

We have also seen little research to date on how people utilize mobile video chat to share experiences when away from their home where the experiences go beyond just conversing. Notable exceptions include the Peek-A-Boo system, which supported a video link between a smartphone and an in-home picture frame to share outdoor activities (e.g., child soccer games) with a grandparent at home [12]. Experiences2Go also provided a live-video feed between a mobile device and an in-home display for similar sharing purposes [6]. There also exist online reports of the unique ways in which Google+ Hangouts is being used for "Virtual Photo Walks" [17] where a person shares video of an 


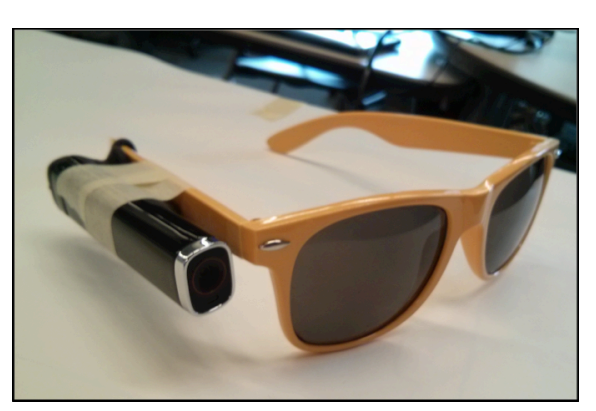

Figure 2: A Looxcie 2 camera attached to a pair of sunglasses.

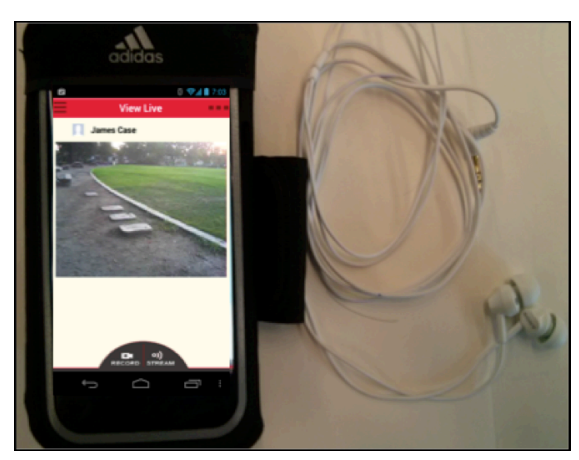

Figure 3: The armband containing a smartphone along with earphones. experience with people who are unable to leave their home (e.g., on bed-rest). While these systems and experiences are valuable, they all explore situations where one person is at home and another is mobile. In contrast, shared geocaching explores parallel experiences where both people are out and actively participating in the same activity at the same time.

\section{Shared Geocaching Technology Probe}

To explore shared geocaching, we created a technology probe shown in Figure 1 that consisted of existing commercial software and hardware. It included a wearable mobile video camera that captured the wearer's field of vision by being attached to an article of clothing such as a hat or a pair of glasses. We used a Looxcie 2 camera and an ordinary pair of sunglasses to prototype the experience (Figure 2).

Using a Bluetooth connection and a specially designed smartphone application (by Looxcie), the camera transmits live streaming video to a local smartphone. By leveraging the smartphone's mobile Internet connection, the application broadcasts the video to a remote user's smartphone at $640 \times 480$ resolution and $24 \mathrm{fps}$, in the best case. At times, this resolution is algorithmically reduced if network bandwidth becomes constrained. The camera also captures and transmits audio to the remote person, so users can talk to one another throughout the experience. Both parties can send and receive video simultaneously to establish a symmetrical exchange where each can view the other's field of vision.

We modified a wearable runner's armband to hold a smartphone that shows the remote user's video (Figure 3 ). This frees up the users' hands to hold a GPS device (for geocaching) if they want to. It also allows them to look periodically at the remote user's video by looking at one's arm. This contrasts a head-mounted display (e.g., smartphone attached to a helmet, or augmentedreality glasses), as we wanted to make video selectively available to users. Thus, they can choose when to look at the remote user's video feed. This also means that the video feed does not obscure a person's normal vision.

Even though our technology probe looks rudimentary, it has allowed us to explore shared geocaching without investing in large development efforts. This is an important goal for technology probes [10].

\section{Participating in Shared Geocaching}

In shared geocaching, players participate with a remote person where each searches for a hidden geocache in his or her own geographic area. Video streaming allows each player to see the remote location and exchange conversation with the other player. It is largely impractical to have identical geocaches in multiple locations so that people search for the 'same' geocache yet in different areas. Instead, we imagine that people will be looking for different geocaches where they use the video streaming system to help each other out and share the experience of geocaching.

Our initial explorations have found that people highly value the shared experience of geocaching with others, especially if they are not able to play with them in faceto-face situations. The video stream, including the audio and video link, provides a strong sense of intimacy with the remote player. This connection is so strong that, in some situations, players forget about 
the 'outside world' because they are so focused on experiencing the situation with their remote partner.

\section{Acknowledgments}

We thank members of the Connections Lab for their support with this research. We also thank the GRAND Network of Centres of Excellence and the Natural Sciences and Engineering Research Council of Canada for funding this research. And, a special thanks to Trevor Komori for his videography and editing work!

\section{References}

[1] Ames, M., Go, J., Kaye, J., \& Spasojevic, M. Making Love in the Network Closet: The Benefits and Work of Family Videochat. Proc. CSCW, ACM Press (2010).

[2] Brubaker, J., Venolia, G., and Tang, J. Focusing on Shared Experiences: Moving Beyond the Camera in Video Communication, Proc. DIS, ACM Press (2012). [3] Buhler, T., Neustaedter, C., and Hillman, S. How and Why Teenagers Use Video Chat, Proc. CSCW, (2012).

[4] Chavez, D.J., Courtright, R., and Schneider, I. Over the River and through the Woods, Parks \& Recreation, 39, 4 (2004), 68-72.

[5] Chavez, D.J., Schneider, I., and Powell, T. The Social Psychology of a Technology Driven Outdoor Trend: Geocaching in the USA, Proc. HICSS 2004, ACM Press (2004).

[6] Inkpen, K., Taylor, B., Junuzovic, S., Tang, J., and Venolia, G. Experiences2Go: Sharing Kids' Activities Outside the Home with Remote Family Members, Proc. CSCW, ACM Press (2013).

[7] Judge, T.K., and Neustaedter, C., Sharing Conversations and Sharing Life: Video Conferencing in the Home, Proc. of CHI, ACM Press (2010).
[8] Judge, T.K., Neustaedter, C. and Kurtz, A., The Family Window: The Design and Evaluation of a Domestic Media Space. Proc. CHI, ACM Press (2010).

[9] Judge, T.K., Neustaedter, C., Harrison, S., and Blose, A., The Family Portals: Connecting Families Through a Multifamily Media Space. Proc. ACM CHI, (2011).

[10] Hutchinson, H., Mackay, W., Westerlund, B., Bederson, B., Druin, A., Plaisant, C., Beaudouin-Lafon, M., Conversy, S., Evans, H., Hansen, H., Roussel, N., Eiderbäck, B. Technology probes: Inspiring design for and with families, Proc. CHI, ACM Press (2003), 17-24.

[11] Neustaedter, C., and Greenberg, S., Intimacy in Long-Distance Relationships over Video Chat, Proc. CHI, ACM Press (2012).

[12] Neustaedter, C. and Judge, T. Peek-A-Boo: The Design of a Mobile Family Media Space, Video Proc. Ubicomp, Springer (2010).

[13] Neustaedter, C., Tang, A., and Judge. T, The Role of Community and Groupware in Geocache Creation and Maintenance, Proc. CHI 2010, ACM Press (2010).

[14] O'Brien, S., and Mueller, F. Jogging the Distance, Proc. CHI, ACM Press (2007).

[15] O'Hara, K. Understanding Geocaching Practices and Motivations, Proc. CHI 2008, ACM Press (2008).

[16] Raffle, H., Ballagas, R., Revelle, G., Horii, H., Follmer, S., Go, J., Reardon, E., Mori, K., Kaye, J., and Spasojevic, M. Family story play: reading with children, Proc. CHI, ACM Press (2010).

[17] Virtual Photo Walks, www.virtualphotowalks.org

[18] Yarosh, S., Inkpen, K., and Brush, A.J., Video Playdate: Toward Free Play Across Distance, Proc. CHI, ACM Press (2010). 